\title{
Editor's Note: Stepping Backward and Moving Forward
}

The five essays in this issue are quite diverse in terms of subject matter, context, and approach. However, if there is one aspect that links them, it is a concern with historical framing, whether it is to shed new light on a subject through a critical analysis of certain shifts in recent dance practices by addressing the historical precedents from whence they emerged (Kloetzel, Haitzinger, Joncheere), or to bring to our attention the importance of a highly regarded performer or author in their day, who somehow got lost in in the mist of time and is now being brought back into the light (Burden, Saumaa). The authors hail from the Canada, Austria, Belgium, Britain, and USA, thus continuing the international focus of the journal.

In the first article, Melanie Kloetzel, takes her point of departure from the increasing interest in and development and diversification of "site dance" in recent years, with presenters and dance festival directors, etc., progressively attracted to staging dance outside of the confines of the theater, in the hope of attracting a broader audience base to dance. Kloetzel shows how these groups, along with choreographers, have pressed the boundaries and margins of "site-specific dance," where the dance created is generally viewed as a direct response to or negotiation with the environment in which it is made. As a result, as Kloetzel points out, a larger lexicon has emerged to accommodate the new directions. The focus of this article, "dance on tour" or "site-adaptive dance," as Kloetzel calls it, is much more difficult to pin down than some of the other terms coined to cover the diversification in dance on site. Kloetzel traces the historical precedents from "site-specific" dance to the "turn to site mobility" (for performers and audiences), "serialization," and "site-adaptive" dance, noting that there was already a visible tendency toward "adaption" in earlier dance site work by, for example, Trisha Brown. Kloetzel examines how this became more pronounced in the work of key arts exponents such as Ann Carlson, Pearson Widrig Dance Theater, Eiko \& Koma, Stephen Koplowitz, and in her own work. Given the increasing tendency to "tour" site dance, Kloetzel argues strongly for a "thorough examination for serialized site work to take place."

Nicole Haitzinger's article also begins from the present time by evaluating two contemporary dance works that offer a critique of the "negrophilic" outlook embedded in European dance productions of the 1920s: Faustin Linyekula's La Création du Monde 1923-2012 and Vera Mantero's one mysterious thing said e.e. cummings (2002). She compares and contrasts these works through a theoretical "re-reading" of the 1920s dance productions these choreographers respectively comment on, the futurist La Création du Monde (1923), choreographed by Jean Börlin for Ballet Suédois, and the performances of Josephine Baker. Adopting Brenda Dixon Gottschild's construct of "Africanistic" and a "post-colonial reading of the cultural memory of dance," Haitzinger argues that there is a tendency in the contemporary works to "essentialize" or "stereotype" the "staging" of Africa in the 1920s through a mistranslation of their historical references, which she shows have more in common with the idea of "plurality in the Africanist sense." Linyekula's and Mantero's productions, for Haitzinger, speak more to the complex relationships between art and politics in the present day than presenting a "faithful" account of their historical examples. 
In the third article, Ayla Joncheere traces what her research reveals to be the recent invention and development of Kalbeliya Dance from Rajasthan since the late 1980s and its subsequent legitimation as an "intangible cultural heritage" by UNESCO in 2010, which bestowed on it the status of an "ancient tradition from India." Joncheere tells us that she became fascinated by Kalbeliya dance after watching a video of it at twelve years of age. Several years later, she ended up performing with Rajasthani performers who visited Europe to perform in international world music festivals. From there, she continued what she terms as her "unconscious fieldwork" by traveling to and living with Kalbeliya dance families in Jodhpur, before she developed her more "formal" ethnographic research. Thus, the article, I suggest, involves at once an auto-ethnographic frame of reference, which provided the author with ease of access to performers, festival producers, promoters, etc., and a more formal ethnographic voice that facilitated what Clifford Geertz $(1975,6)$ called "thick description." Joncheere's in-depth analysis reveals how Kalbeliya "dance finds itself at the crossroads of commercial tourism and political folklorism, and is grounded in neo-orientalist discourses (romanticism and exoticism)."

The penultimate article by Michael Burden takes us back to the 1784-1785 season in London when, as the author notes, "there was a conjunction between Shakespeare's Macbeth and three of the most thrilling artists of the eighteenth century," namely Geltruda Rossi, the dancer; Sarah Siddons, the "actress"; and Henry Fuseli, the artist. This juxtaposition, which Burden meticulously fleshes out in his article, stemmed from a "short article" on Rossi's benefit performance in London on March19, 1785, in which the anonymous reviewer commented that the dancer's impressive performance of Lady Macbeth reminded him (sic) more of Fuseli's painting of Lady Macbeth walking in her sleep than Sarah Siddons' performance of that scene, which Siddons also presented for her benefit performance in London on February 15, 1785. In addition to fleshing out the artists' biography, Burden's article, as one reviewer noted, brings into focus "several different theatrical disciplinesmusic, costume design, dance, acting technique, [and] theatre management," all of which are important, "given that the intersection of those disciplines was fundamental to production in that era." The "short article," as Burden notes, provides a glimpse of Rossi's performance, of which little is known, unlike that of Siddons' or Fuseli's. It offers an example of eighteenth century London ballet d'action and, as Burden suggests, is worthy of exploration.

The final article by Hiie Saumaa focuses on the work of Annie Payson Call (1853-1940), a teacher and a profuse, widely read author, whose approach to "bodily education" was extremely popular in the United States, although she is a "forgotten figure" today. Saumaa positions Call's training method for the education of bodies in relation to American Delsartism and the many popularized physical health movements and dance innovations toward the end of the nineteenth century and the early decades of the twentieth century. Saumaa examines Call's conceptual "movement philosophy" and the training method she advocated to gain awareness of the body and the release of muscular tension. The article analyzes the importance of the use of "imaginative" or poetic language in Call's writing and the invocation of the imagination as key factors in the training of bodily awareness and muscle relaxation, thus, bringing together the mind and the body to invoke bodily awareness. Saumaa sees that Call's attention to language and the imagination in her writing is not only there to impart information to the reader, but also to "help the reader's somatic imagination through her poetical, evocative language and narrative structures," which is, for Saumaa, "a form of somatic training in itself."

As the first issue of 2017 goes to press with me as editor, I wish to acknowledge Mark Franko's outstanding contribution to the journal during his lengthy editorship period (January 2009December 2016). As Chair of the Editorial Board from 2010-2016, I learned a great deal from Mark on journal-related matters. Over the past year, I have been receiving articles submitted to the journal from Mark and his editorial assistants, and have witnessed the staged process of the editorial submissions to Cambridge University Press. I want to thank Mark and his team for providing the necessary tools to guide me through the management of this issue. Mark is indeed a hard act to 
follow. I am honored to take on the role of Editor of Dance Research Journal and hope I can make it work as well as Mark and the previous incumbents, who also contributed much to the development of this highly regarded journal.

Helen Thomas

Editor, Dance Research Journal

\section{Work Cited}

Geertz, Clifford. 1975. The Interpretation of Cultures. London: Hutchinson \& Co. 


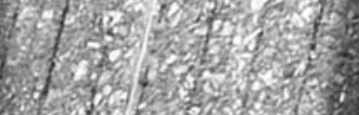

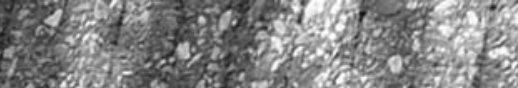

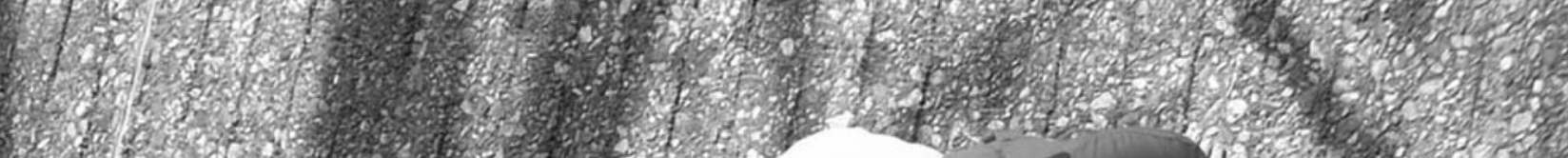

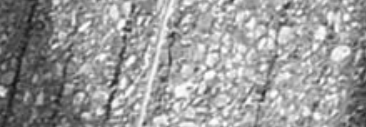

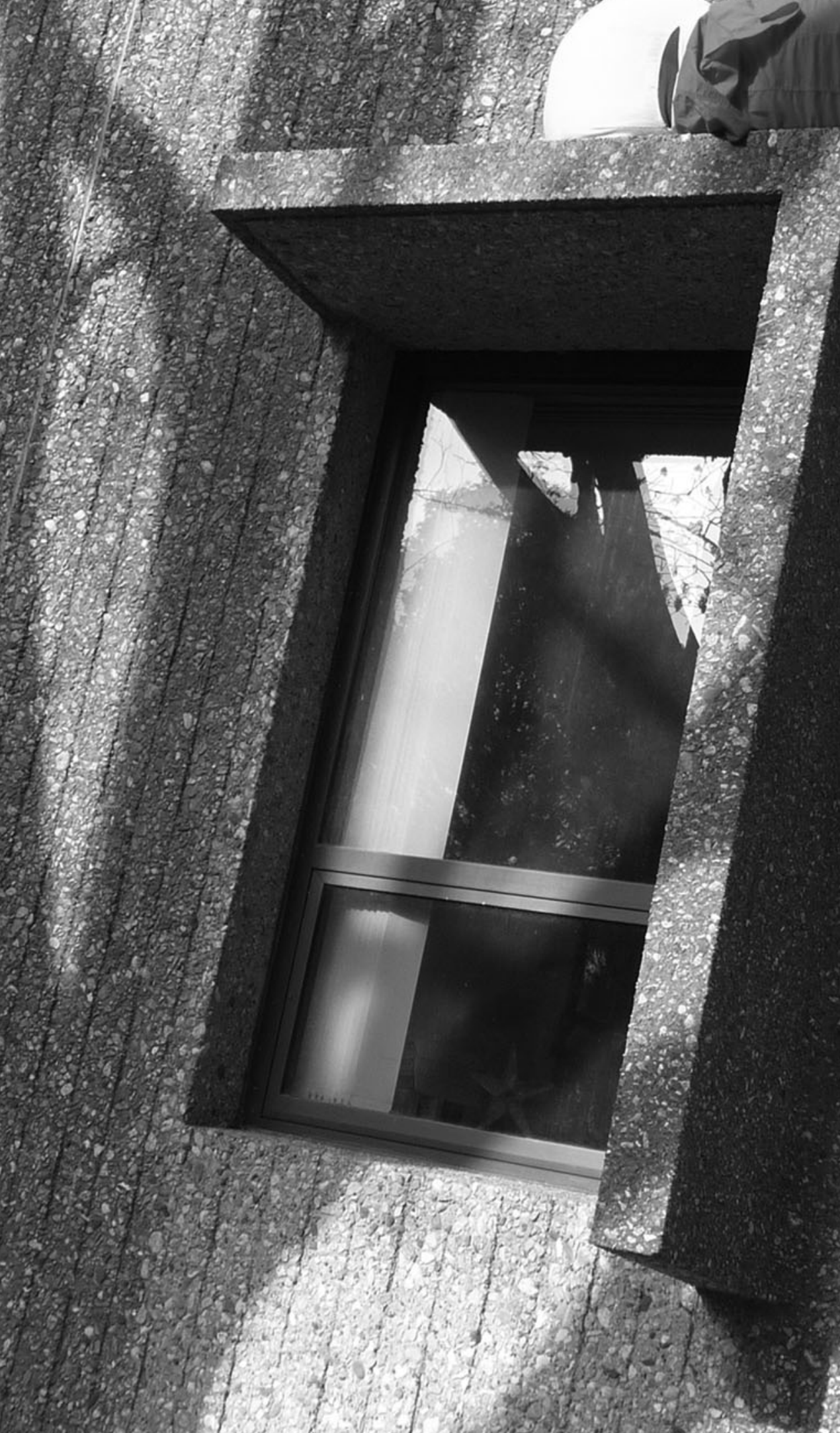

